\title{
Repetitive Aspiration Pneumonia Caused by Basilar Impression
}

Hiroki Kawabata, Takashi Matsunaga, Konomi Sennari and Kazuhiro Yatera

Key words: basilar impression, aspiration pneumonia

(Intern Med 57: 3221-3222, 2018)

(DOI: 10.2169/internalmedicine.9429-17)
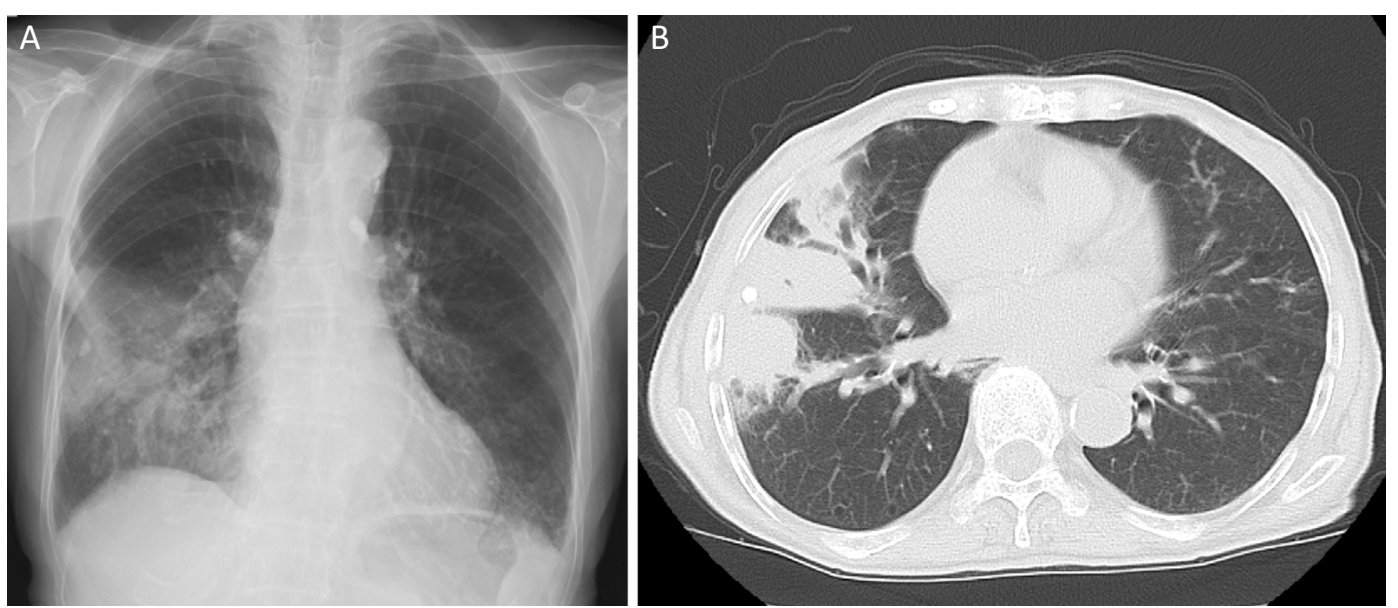

Picture 1.
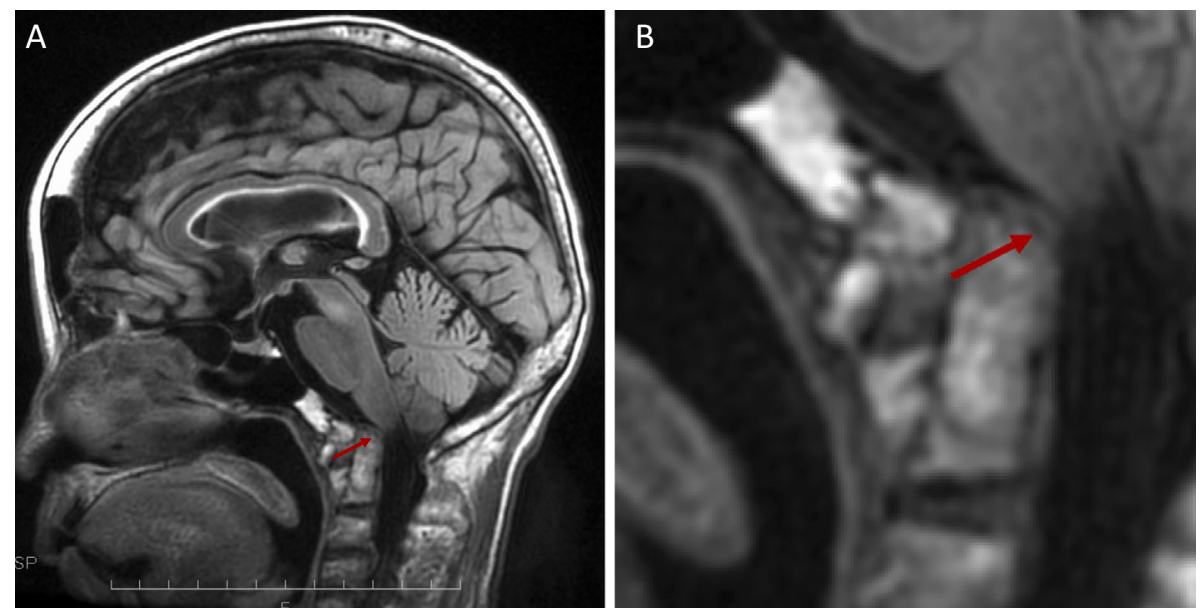

Picture 2.

A 78-year-old woman was evaluated for chest infiltration. dysphagia for six months before admission. Chest radioShe had had repetitive febrile productive cough and graph revealed infiltrative shadows (Picture 1A) with right 
middle lobe and lower lobe infiltrative opacity on computed tomography (Picture 1B). Antibiotic therapy was successful, but she was readmitted two weeks later for repetitive febrile productive cough. A swallowing radiographic contrast study confirmed pharyngeal-stage swallowing dysphagia. Magnetic resonance imaging (Picture $2 \mathrm{~A}$ and $\mathrm{B}$, enlarged view) revealed that the tip of the odontoid process (arrow) was oppressing the lower part of the medulla, but no organic brain lesions were found. Basilar impression is usually asymptomatic, but compression of the medulla by the odontoid process can cause bulbar paralysis, including dysphagia (1). Why the medulla had become oppressed by the odontoid process was unclear. Further clinical experiences are needed to clar- ify the cause of medullar oppression by the odontoid process.

The authors state that they have no Conflict of Interest (COI).

\section{Reference}

1. O'Connell JE, Turner JW. Basilar impression of the skull. Brain 73: 405-426, 1950.

The Internal Medicine is an Open Access journal distributed under the Creative Commons Attribution-NonCommercial-NoDerivatives 4.0 International License. To view the details of this license, please visit (https://creativecommons.org/licenses/ by-nc-nd/4.0/).

(C) 2018 The Japanese Society of Internal Medicine Intern Med 57: 3221-3222, 2018 